\section{William Shockley (1910-1989)}

William Shockley, who died on 11 August in California, must have been one of the most controversial scientists of this century. He collaborated with John Bardeen and Walter Brittain in the invention of the transistor, which has revolutionized modern life. As a driving force behind the exploitation of miniaturized electronics, he was sometimes called the father of silicon valley. But in the last decades of his life, these achievements became overshadowed by the notoriety of his views on racial differences.

It seems that, having gained the Nobel Prize for physics for his work on transistors, Shockley developed an affliction, shared by a few other laureates, that is rooted in public reverence for the prize. The victims (so far, always male) note that their opinions on almost any subject are treated with respect, even in fields in which they have no expertise; and deciding that one of these fields is dominated by stick-in-the-muds, they propose to bring them a breath of fresh air.

Shockley selected social anthropology and genetics. Human intelligence, he proposed, is inherited, and blacks are genetically inferior in intellect to whites: "genetics plays a role in the disadvantages of our nation's black minority. My research on IQ and race gives the estimate that, in negro populations with average IQs in the 70 to 90 range, each additional 1 per cent of caucasian ancestry raises average IQ by 1 per cent"1. The latter point he made in spite of the wide margin of error in IQ measurements. Shockley proposed a "voluntary sterilization bonus plan . based on payments of a thousand dollars for each point below 100 IQ".

McClelland's view ${ }^{2}$, that IQ measurements are "part of an elitist mechanism to discriminate against the disadvantaged" typifies the low value specialists place on IQ measurements. The allegation that any ethnic group has an hereditary lack of intelligence is contrary to measurements of human genetic variation. For example, the estimated number of gene differences between individuals from different populations (caucasian, negro, Japanese) is only slightly greater than the number between individuals from the same population $^{3}$. Furthermore, the allegation goes against people's aspirations towards unity. As a result, Shockley's lectures caused near-riots at campuses.

Shockley admitted in 1965 "several intellectuals have discouraged me from publicly expressing" the ideas, but added "I have faith in the long-term values of open discussion"4. Although his ideas, which were not novel, were examined and rejected, he continued to advance them.

More palatable than his ethnic proposals were Shockley's views on the inheritance of genius. The emergence of genius that transcends circumstances is well known. Examples include the mathematician Ramanujan and, in music, Mozart.

Shockley evidently favoured the idea that the genes that produce geniuses

\section{IMAGE \\ UNAVAILABLE FOR COPYRIGHT REASONS}

William Shockley - notorious views.

should be passed on to offspring through insemination, making, at the age of 68 , a personal contribution to this effort via a sperm bank in Southern California. This donation he discussed at length in an interview with Playboy magazine 5 . Younger donors are usually preferred because of the lower count of viable spermatozoa in older men, not to mention unsubstantiated speculation that deleterious mutations may accumulate in the germ line. (There is also the problem of genetic recombination, famously noted once by George Bernard Shaw. It is claimed that the beautiful actress Ellen Terry expressed a wish to mother a child by him that would have her looks and his brains. Shaw's diffident reply was that he feared the child might have his looks and her brains.)

Shockley argued that "the breeding of good genetic material, whether the people are rich or poor, is desirable. We want more Lincolns, not fewer", and bolstered this simplistic approach by quoting Herman Muller whose advocacy of eugenics is generally rejected, in spite of his eminence in genetics.

It is regrettable that Shockley's great contribution to the 'transistor age' is marred by his ideas on genetics. Astonishingly, he viewed' his theories of 'dysgenics' as more important than his work on the transistor, and continued to publicize these ideas at the same time as another Nobel laureate, Martin Luther King, led us in the opposite direction. H. Kallikak

1. Shockley, W. The Humanist 32, 16-17 (1972).
2. McClelland, D.C. The Humanist 32, 9-10 (1972).

3. Nei, M. \& Roychoudhury, A.R. Science 177, 434-436 (1972)

4. US News \& World Report 59, 68 (22 November 1965)

5. Playboy 27,69-87 (August 1980)
OUR sense of touch is almost totally ignored by modern information technology, except in the special case of Braille for fingertip reading. Daedalus sees this as a lost opportunity. He points out that touch is most discriminating, not at the fingertips at all, but at the tongue. We all know how instantly the tongue detects and explores the smallest dental changes: persistently reminding us, for example, of a tiny chip lost from a tooth. Dental patients often complain of irregularities in a new filling that the dentist can hardly even see.

So Daedalus is devising a new communication device, the DREADCO Datadenture. His prototype has a datahead, resembling the printing head of a dot-matrix printer, mounted in the centre of its dental plate. A matrix of tiny pins, each capable of independent vertical travel, can present the tongue with a wide range of possible conformations. Toothless volunteers and DREADCO dentists are cooperating to discover how many configurations of the active surface can be distinguished and how rapidly, what codings are most easily learnt, and so on.

The prototype gets its power and information from a rather clumsy cable entering the mouth. The final design, more elegantly, will use magnetic induction. The primary of the drive-transformer will be mounted on the wearer's collar, and will energize the pin-actuating coils in the wearer's mouth as secondaries. Each drivecoil will be given a different resonant frequency, so that the induction link can address them all individually by simple frequency modulation. All the coding circuits and power-supply units would be safely outside the body, so that the mouthborne data head may even be miniaturized to the size of a single tooth filling. In exchange for this much more modest dental sacrifice, the wearer would gain a wonderful private data-link, fed from information relayed to the collar induction unit by a nearby transmitter.

At first Daedalus saw his dental datalink as an exotic private paging device, perhaps calling the ambassador unobtrusively from the embassy party to cope with sudden international crises. Less romantically, he now sees it as a source of steadily updated 'background information' for working professionals: giving the time or the stock-market prices, the changing output of a plant or the speed and heading of an aircraft. The user would soon learn to 'read' it quite automatically, while coping with foreground tasks, scanning instruments or talking to colleagues. This parallel data-path would be wonderfully clear and distinct; even in confusion or dark or deafening noise, the private 'voice in the mouth' would continue to speak.

David Jones 